\title{
The Reaserch on Characteristics of Knowledge Workers and Their Motivating Factors: A Review and Comparison Study
}

\author{
Hong Zhan', Tian Tang ${ }^{1}$, Yue Zhang ${ }^{2}$ \\ ${ }^{1}$ School of Management, Xiamen University, Xiamen, Fujian, China; ${ }^{2}$ California State University, Northridge. USA. \\ Email: Zhanhong@xmu.edu.cn, Tang19870804@yahoo.com.cn,jeff.zhang@csun.edu
}

Received August $1^{\text {st }}, 2013$; revised September $1^{\text {st }}, 2013$; accepted October $2^{\text {nd }}, 2013$

Copyright (C) 2013 Hong Zhan et al. This is an open access article distributed under the Creative Commons Attribution License, which permits unrestricted use, distribution, and reproduction in any medium, provided the original work is properly cited.

\begin{abstract}
The current study surveyed major studies on the characteristics of motivating factors for knowledge workers, both in the USA and in China. Comparisons were made between studies in the two countries, and new perspectives were offered on the motivating factors for knowledge workers. Future research directions were proposed.
\end{abstract}

Keywords: Knowledge Workers' Characteristics; Motivating Factors; Comparison of Incentive Preference

\section{Introduction}

As early as in the 1950s, Peter Drucker pointed out that "the most important contribution of management was to increase the productivity of laborers by fifty times. In the $21^{\text {st }}$ century, however, the most important assets of organizations are knowledge workers, and their productivity. The most important thing management needs to do, therefore, is to improve the productivity of knowledge workers" [1]. On entering the second decade of the $21^{\text {st }}$ century, the roles of knowledge workers are increasingly prominent. CCP, the ruling party of China, explicitly had "strengthening China through science and education and through developing Chinese talents" as its strategy. By the same token, The Mid-to-Long-Term National Educa tion Development Program (2010-2020) of China further emphasized the development of Chinese intellectual talents. The current study will review the literatures, both Chinese and abroad, on the characteristics of knowledge workers, and based on the review and comparison, identify the preferences of knowledge workers for motivating factors. This paper will answer the 4 questions as below: Who are knowledge workers? What are the typical characteristics of knowledge workers? What are knowledge workers incentive preferences?

\section{The Definition and Characteristics of Knowledge Worker}

\subsection{Defining the Knowledge Worker from Different Views}

"Knowledge worker" was first brought forth in Landmarks of Tomorrow: A report on the New Post-Modern World [1,2]. Later, many western scholars like Kidd [3], Vogt [4], Dove [5], David [6], Itzhak [7], John [8], Patricia [9] and Davenport [10] conducted further studies about knowledge worker's performance, motivation, and other related issues. In China, "knowledge worker" is a borrowed word, but similar words such as "intellectuals" and "brainworkers" have been used for years. Reviewing relevant literature, the definitions of knowledge worker are so diverse that they need to be classified, analyzed, examined, and synthesized.

\subsubsection{Definition Based on the Work Content}

This kind of definition is made from several specific points of view, such as job contents, the way to complete the work, and work process. Drucker [11] referred to an individual who works primarily with information or one who develops and uses knowledge in the workplace as the knowledge worker. Yang et al. [12,13] emphasized 
on the properties of work content, and considered knowledge worker as the staff who engages in knowledge work. Based on this definition, Sun [14] held an opinion that the staff that directly takes part in knowledge work and follows this work as a profession can be called knowledge worker, such as a scientist, a teacher, and an engineer. He emphasized on the profession, to distinguish from an amateur, who does not take up knowledge work as a career. This view highlights the nature of work; but understanding of the work content is not complete and neither in sufficient depth. The meaning from this view is somewhat imbalanced.

\subsubsection{Definition Based on the Work Output}

The work output could be understood as an outcome for the organization the worker is working for. This kind of definition is outcome-oriented. J. Davies et al. [15] proposed that the knowledge worker is coming with the increment of knowledge capital and bringing high added value. $\mathrm{Xu}$ and $\mathrm{Zhu}[16]$ believed the knowledge worker is similar to the occupational brainworker, who makes creative contribution, brings a strong value-added growth of knowledge capital and monetary capital. From this view, one can easily distinguish two extremes of, say, scientists form porters; but there could be gray area between brainworkers and labors, especially in today's computing age when many workers are using a computer to do their job. These grey areas could not be explained accurately here.

\subsubsection{Definition Based on the Individual Characteristics}

Researchers in this view summed up more general characteristics of knowledge workers from specific cases, and then made the definition of knowledge workers. Accenture (2008) defined knowledge workers as the staff who complete tasks with intellectual input, creativity, authority, including the professional, the paraprofessional with depth skills, and the senior manager. This type of workers always work in fields such as R \& D, engineering design, marketing, legal service and management consulting. Cai [17] considered that knowledge workers have high degree of human capital and pursue independence, creativity, personalization, and diverse work contents. They create value by using knowledge and information. They keep on learning and creating to adapt to the complex and dynamic changes. Zhou [18] believed that knowledge workers accept systematic learning of theory and professional skills, and build up an effective knowledge structure. Knowledge workers can leverage modern sciences to achieve productivity - education was introduced in this definition. The definitions from this dimension have their advantages of being operational, that the dimension is commonly used in empirical researches. There are two shortcomings: first, there exist dozens of characteristics for knowledge workers; second, different scholars emphasized on different characteristics. Therefore, it is difficult to reach a consensus of the definition.

We believe that the above schools of thoughts can be synthesized, and a definition of knowledge worker can be like the following: they are workers who produce high value-added products and services with knowledge and ability, and keep on updating their knowledge and improving their abilities to adapt to the complex tasks and diverse work environments.

\subsection{A Meta-Analysis of Knowledge Workers' Characteristics}

Existing numerous studies on knowledge worker's characteristics offer no conclusion of consent. In this study, we will summarize the characteristics by a meta-analysis. First, we used China National Knowledge Infrastructure (CNKI) as the database to conduct the search, for which we chose the fields of economy and management the scope for literature. Second, conducted an advanced search using the subjects "knowledge worker \& characteristic", with 2000-2009. Third, listed the search results on citation frequency and downloaded the $1^{\text {st }}-100^{\text {th }}$ articles. Forth, skimmed through the literature and use "original study on characteristics of knowledge worker, rather than citing others' work" as the criterion, which cut down the number of articles to 64 . We also studied in details the top-three ranked articles.

Using statistical analysis, we identified 35 characteristics for knowledge workers. Those characteristics appeared in more than 10 studies are presented in Table 1.

\subsubsection{Knowledge Workers Are More Independent}

Compared with other types of employees, knowledge workers enjoy the rights and power to be in control of their work. In addition, they are held fully responsible for their work. "Independence" also means that knowledge workers prefer to be self-governing and self-control rather than being affixed to machines as line workers [19]. Peng [20] pointed out that knowledge workers' independence is characterized by the act of empowerment. Empowerment has risks, because choosing the wrong person for the job can jeopardize the performance of the company.

\subsubsection{Knowledge Workers Tend to More Loyal to the Occupation Instead of Employer; High Level of Turnover}

Knowledge workers' high turnover rate brings a challenge to the traditional employment relation. Of Industrial economy when mass production was the defining 
The Reaserch on Characteristics of Knowledge Workers and Their

Motivating Factors: A Review and Comparison Study

Table 1. The characteristics of knowledge workers.

\begin{tabular}{|c|c|c|c|c|c|}
\hline Rank & Frequency( $($ ) & Characteristics & Jiang et al. & Lin & Peng \\
\hline 1 & 45 & Independence & $\sqrt{ }$ & $\sqrt{ }$ & $\sqrt{ }$ \\
\hline 2 & 39 & High level of turnover & $\sqrt{ }$ & $\sqrt{ }$ & $\sqrt{ }$ \\
\hline 3 & 30 & Creativity & & & \\
\hline 4 & 30 & Being difficult to supervise the work processes & & $\sqrt{ }$ & $\sqrt{ }$ \\
\hline 5 & 29 & Realizing self-value & $\sqrt{ }$ & $\sqrt{ }$ & \\
\hline 6 & 26 & Being difficult to measure the work results & & $\sqrt{ }$ & $\sqrt{ }$ \\
\hline 7 & 23 & Knowledge capital & & $\sqrt{ }$ & $\sqrt{ }$ \\
\hline 8 & 15 & Dimly bounds of leadership and being contemptuous of the authority & & $\sqrt{ }$ & $\sqrt{ }$ \\
\hline 9 & 13 & Being loyal to the occupations instead of employers & $\sqrt{ }$ & & $\sqrt{ }$ \\
\hline 10 & 13 & Individual characters & & $\sqrt{ }$ & \\
\hline
\end{tabular}

(") The number of articles containing the character.

feature, tools, machines, and materials belonged to capital. The skilled employees cannot function without physical capital, such as machines, raw materials and physical plant [21]. Of knowledge economy, the knowledge employees are prominent in the most important knowledge, which is deeply ingrained in their mind. Because of this, they are much more powerful to select opportunities, far more than the traditional workers [19,22].

\subsubsection{Knowledge Workers are Difficult in Supervising the Work Processes and Measuring the Work Performance}

Knowledge workers use their brains to think and make decision. It is different to accurately judge the level of their work efforts and efficiency. Lin [19] and Cao [23] pointed out that it did not make much sense, and not very probable either, to monitor and control the work process of knowledge workers. Thus, the measurement of work result is another thorny problem. Firstly, the work product is the result of teamwork, instead of that of one individual's, so it is hard to measure individual contribution [23]. Secondly, unlike in the case of laborers, quantified process of work performance is difficult [24].

\subsubsection{Knowledge Workers Pursue Self-Actualization}

Knowledge workers have a strong will to realize their own goals; they strive for being recognized by professional peers through their own efforts [23]. From the analysis of costs and benefits, knowledge workers should pay cost of education and training during the process of acquiring knowledge and skills, and also opportunity cost of no income as well as costs of psychological struggles. Consequently they have expectations to achieve high earnings. This earning not only means wealth and social position, but also the compensation covering psychological costs [25]. Therefore, they prefer well-paid work with challenges.

\subsubsection{Knowledge Workers Possess Knowledge Capital}

The greatest wealth of knowledge workers is the knowledge which they own. There are two aspects mainly to be shown as blew:

First, knowledge workers who are usually well educated, master certain professional knowledge and skills; and most of them have quite good personal qualities, such as the broad vision, strong thirst of knowledge and learning ability, broad knowledge level, etc. Organizations promote knowledge workers to turn their ideas, creativity, knowledge and experience into the source and motivation of the organizational development through the provision of resources and platform.

Second, the knowledge workers possess knowledge characterized with the rapid development and change, so knowledge workers have been in the status of self-development and constantly knowledge updating in a long period, which is equivalent to continuously inject fresh blood for the development of organization. It determines the developing direction and trends of the company's future.

\subsubsection{Blurring of the Boundary with Leadership and Defying Administrative Authority}

Knowledge workers see their relationships with the administration as an interaction with no fixed authority [26]. Knowledge is replacing administrative authority to be the only judgment standard of merits. Knowledge workers can affect their superiors, peers, and subordinates with professional knowledge and skills. So they see the boundary among classes in the traditional bureaucratic enterprise becoming blurry, and the administrative authority no longer has absolute control.

There are two reasons that it is highly complex in the area of characteristics of knowledge workers: firstly, different researchers had different criteria for classifica- 
tion, which lead to the overlapping contents of different characteristics; secondly, neglected the interrelationship and causality among the characteristics causing the ambiguity in identifying truly distinct characteristics.

\section{The Research Status on Knowledge Workers Incentive Preferences in China}

In the same range of information search conducted for the study in the previous section, we conducted an advanced search with the subjects being "knowledge worker \& motivation" or "knowledge worker \& incentive", with the time frame being 2000-2013. There were 256 articles published in academic journals on the subjects in that time frame. After eliminating the papers not directly relevant to the current research topic, 219 articles were selected as shown in Table 2.There were few researches on knowledge workers' motivation in China before 2000. During 2004-2009, the number of relevant articles increased significantly, due to the rapid economic development of the period, and the large number of college graduates entering the workforce which caused the management's attention to the issue of managing knowledge workers [27].

\section{The Comparison of Incentive Preference of Knowledge Workers between China and The West}

Researchers in western countries conducted a great deal of empirical research on factors with effective incentives for knowledge workers, covered different professions such as college faculty, engineers, software designers in the USA, UK, Australia and Japan. The representative incentive preferences are shown in Table 3 and 4, from overseas and Chinese researches respectively.

\subsection{The Common Incentive Preferences of Knowledge Workers}

Researchers in western countries conducted a great deal of empirical research on factors with effective incentives for knowledge workers, covered different professions

Table 2. The quantity of articles published 2000-2013.

\begin{tabular}{ccc}
\hline Year & Article quantity & Percentage in the total \\
\hline $2001-2004$ & 17 & 7.76 \\
$2005-2009$ & 135 & 61.64 \\
$2010-2013$ & 67 & 30.59 \\
Summation & $\mathbf{2 1 9}$ & $\mathbf{1 0 0 \%}$ \\
\hline
\end{tabular}

such as college faculty, engineers, software designers in the USA, UK, Australia and Japan. The representative incentive preferences are shown in Table 3 and 4, from overseas and Chinese researches respectively.

\subsubsection{Personal Growth and Development}

This factor is constantly on top three in all the studies mentioned above. Knowledge workers have high quality and technical skill, and to remain competitive they are pursuit non-stop with the growth of knowledge, individual, and professional achievement. Tampoe [28] found that $33.73 \%$ knowledge workers chose personal growth as the most important incentive factor. Andersen Consulting (1994) study 858 knowledge workers from Australia, U.S.A., Singapore, Japan, Korea, and Hong Kong about the incentive factors, and found that promotion, considered as a form of personal development, took the third place. This study was conducted in different cultural and economic backgrounds, so the results have cultural applicability. Peng and Zhang (1999) [29] survey $150 \mathrm{R} \& \mathrm{D}$ workers from four major technology companies about incentive factors, and found personal growth and development ranked number two. Deng et al. [30] and Chen and Jing [31] found from the analysis of 302 questionnaires that, professional achievement, work environment, $\mathrm{C} \& \mathrm{~B}$, and personal growth were the four main incentive factors. They also found that different factor preferences exist between age groups - knowledge workers under 39 years preferred C \& B, those under 29 years old valued personal growth more. Based on education background, Zheng and Huang [32], Jiang and Zhao [33], Zhang [34] all found that highly educated workers have stronger needs for growth.

\subsubsection{Job Challenge and Achievement}

Some researchers established knowledge workers' incentive utility function, and indicated that the correlation between job challenge and achievement is positive [35, 36]. They are the decisive factors for the utility's maximization. Xian and Zhang [37], Li and $\mathrm{Yu}$ [38], Shun [39] maintained that the ration and challenge of task design was the key for knowledge workers' morale. Wang et al. [40] suggested that management should gradually increase the level of difficulty and enrich work contents. Furthermore, Chen [41] and Luo [42] defined work enrichment as "the basic change of work content and accountability level, which is also the vertical extension of the responsibility of work." The work giving workers the sense of achievement is always those closely relate to the organizational strategy. Knowledge workers long for their work to be part of the organizational value chain [43], and then grow up with the organization. 
Motivating Factors: A Review and Comparison Study

Table 3. The incentive factor of knowledge workers—studies in other countries.

\begin{tabular}{ccccccc}
\hline Researcher & Time & $\mathbf{1}^{\text {st }}$ & $\mathbf{2}^{\text {nd }}$ & $\mathbf{3}^{\text {rd }}$ & $\mathbf{4}^{\text {th }}$ & $\mathbf{5}^{\text {th }}$ \\
\hline Tampoe & 1989 & Personal growth & Work Independence & Professional Achievement & Wealth & 1 \\
$\begin{array}{c}\text { Andersen } \\
\text { Consulting }\end{array}$ & 1994 & Compensation & Nature of job & Promotion & Peer relationship & Decision participation \\
$\begin{array}{c}\text { Zingheim } \\
2001\end{array}$ & $\begin{array}{l}\text { Attractive development } \\
\text { prospect of the organization }\end{array}$ & Opportunity to grow & $\begin{array}{c}\text { Good working environ- } \\
\text { ment }\end{array}$ & Total compensation & $\backslash$ \\
\hline
\end{tabular}

Table 4. The incentive factor of knowledge workers—studies in China.

\begin{tabular}{|c|c|c|c|c|c|c|}
\hline Researcher & Time & $1^{\text {st }}$ & $2^{\text {nd }}$ & $3^{\text {rd }}$ & $4^{\text {th }}$ & $5^{\text {th }}$ \\
\hline Peng et al. & 2001 & Compensation and bonus & Personal growth & Company prospect & Challenges & Job security and stability \\
\hline $\begin{array}{l}\text { State Council Development } \\
\text { Research Center }\end{array}$ & 2006 & Opportunity to grow & Peer relationship & Sense of accomplishment & Fair evaluation & High pay \\
\hline Wang & 2008 & Compensation \& Benefits & Quality of leaders & Personal growth & Company growth & Safety and security \\
\hline
\end{tabular}

\subsection{The Comparison of Incentive Preferences of Knowledge Workers between China and the West}

\subsubsection{The Deference in Compensation and Wealth}

Chinese knowledge workers place more emphasis in compensation than their foreign counterparts. Yu et al. surveyed 454 samples in the US and 302 in China, and found that "higher compensation ranked number one in Chinese workers, yet was not even in top five among the US workers. The above phenomenon must be because of the economic backgrounds the Chinese workers were in. China is in economic transition period, with relatively low economic development level. In addition, China's economic environment is one that is complex and changeable, with high uncertainty [44]. One must also note that in recent year, monetary reward is not only to satisfy workers' fundamental needs: the amount of compensation is also an important measure of the contribution a worker has made to his/her organization, and a measure of his/her social status [45,46]. Wang and Wang [47] proposed an incentive system combining short-term incentive - skill-based salary - and long-term incentivestock options. Other Chinese studies also found differences in state-owned companies and private companies, as well as regional differences (for example, [48-51]).

\subsubsection{The Differences in Work Independence and Job Security}

Knowledge workers in western countries ranked work independence as among top five factors. This could be closely related to the low uncertainty avoidance, low power distance, and high individualism western culture [52]. Based on this cultural background, knowledge workers value liberty higher, prefer not to be interfered too much by superiors, and are more willing to undertake the consequence of their own decisions. In this situation, is has become urgent to find the balance point between teamwork and independence [53]. As a contrast, Chinese Knowledge workers have high power distance, low individualism and tend to be risk-adverse. Under such cultural backgrounds, Chinese knowledge workers have a great worship of authority, highly hero individualism as well as authoritarianism. They are prudential, industrious, endurance, risk-adverse, ordered and can't stand uncertainty. They often inscribe their success and failure to 'predestined relationship'. Although Chinese knowledge workers also enjoy certain flexibility in career change, because of traditional culture as well as economic development level, jobs with higher security still have greater incentive. It does not mean, however, that Chinese workers do not need the kind of self-empowerment. Traditional 9-to-5 jobs and fixed work location would limit knowledge workers' creativity and idea generation, while flexible schedule can better break the boundaries of time and space to achieve optimal resource allocation [54].

\subsubsection{The Difference in Fairnes}

The factor fairness, although did not enter top five in most of the incentive studies, has been more emphasized by Chinese workers as compared to their international counterparts. The reason why it would be so is that China has its special Guan Xi background, which emphasized maintaining emotional connections and mutuality of interests. In this situation, those workers without Guan Xi would feel or face interference in the relationships of work input and output, in work output and rewards, and in rewards and work satisfaction. Knowledge workers would, likewise, not ignore this important aspect of work environment. Therefore, we should establish more fair evaluation systems to accurately measure the contribution of employees. This is the necessary condition for internal and external fairness.

\subsubsection{The Difference in Working Environment} Compared with American knowledge workers, Chinese 
knowledge workers place more emphasis on working environment and culture environment. This has some relationship with the cultural differences between China and the U.S. The Chinese traditional cultures pay more attention to the solidarity and cooperation, especially emphasis the collectivism education. It also teaches workers to treat the company as their home and carry forward the spirit of ownership, so the organization identity of Chinese knowledge workers is relatively higher. They have a strong collective consciousness and they pursue the personal values embodied in the collective. The American culture emphasis freedom and independence, so the Americans are more inclined to pursue personal fulfillment. There is no strong sense of the belonging to the company in which they work, so they pay more attention to personal development, and place less emphasis on their overall environment.

\subsubsection{The Difference in Decision Participation}

Chinese knowledge workers pay less attention to decision participation than Americans. Maybe it is because the difference of their power distance. Employee motivation also is closely related with power distance within a culture. The large power distance cultures emphasize hierarchy, obedience and authority; whereas the low power distance cultures emphasize equality, fairness and empowerment.

China is characterized by a high power distance culture. People think consciously or unconsciously that there are class differences between authorities and common people. Chinese people think they should follow the decision of their authorities and few of them challenge the thoughts or ideas of authorities. In companies, subordinates shouldn't disobey the boss, not to mention the decision participation. Compared with Chinese culture, American culture has the low power distance. From the government to citizens, equality is emphasized to reduce the power distance among people. The characteristics of knowledge employees determine that most of them value equality and do not subdue authorities, they tend to participate in the decision.

\subsection{Conclusion, Limitation of Incentive Preference Research, and Future Direction}

The studies reviewed above covered many aspects of the issue on knowledge workers' incentive preferences. However, they were almost all on the characteristics of knowledge workers and their needs. Also, they attempted to derive the incentive measures from the two. There had been few that analyzed the incentive factors from the knowledge workers' behavioral dynamics. The situation is changing: literatures on workers' mental bargains are coming out gradually. The current studies on knowledge workers' incentive preferences have a lot of redundancy. The researches in China, especially conceptual studies, can be seen based on or adapted from researches of western countries. "Take the management sciences that originated in the western society, whose social psychology, culture, and behavioral norms are all very different, and introduce them into an environment with totally different psychology and culture, then the introduced management would totally likely be set idle or be distorted". We suggest here that future researches must consider the unique characters and the culture of China, through theoretical and empirical studies, to identify the incentive preferences for China's knowledge workers.

\section{REFERENCES}

[1] P. F. Drucker, "Management Challenges for the 21st Century," China Machine Press, Beijing, 2006.

[2] P. F. Drucker, "Knowledge-Worker Productivity: The Biggest Challenge," California Management Review, Vol. 41, No. 2, 1999, pp. 79-94.

[3] A. Kidd, "The Marks Are on the Knowledge Worker," Proceedings of the SIGCHI Conference on Human Factors in Computing Systems, Vol. 4, 1994, pp. 186-191.

[4] E. E. Vogt, "The Nature of Work in 2010: Knowledge Work," Telecommunications-International, Vol. 2, 1995, pp. 186-191.

[5] R. Dove, "Knowledge Management, Response Ability, and the Agile Enterprise," Journal of Knowledge Management, Vol. 3, No. 1, 1999, pp. 18-35.

[6] D. J. Cooper, J. H. Kagel, W. Lo and Q. L. Gu, "Gaming against Managers in Incentive Systems: Experimental Results with Chinese Students and Chinese Managers," The American Economic Review, Vol. 89, No. 4, 1999, pp. 781-804. http://dx.doi.org/10.1257/aer.89.4.781

[7] I. Harpaz, "The Transformation of Work Values in Israel," Monthly Labor Review, Vol. 122, No. 5, 1999, pp. 46-50.

[8] J. H. Kagel, R. M. Harstad and D. Levin, "Information Impact and Allocation Rules in Auctions with Affiliated Private Values: A Laboratory Study," Econometrical, Vol. 55, No. 6, 1987, pp. 1275-1304.

[9] P. K. Zingheim and J. R. Schuster, "Winning the Talent Game: Total Rewards and the Better Workforce Deal," Compensation and Benefits Management, Vol. 17, No. 3, 2001, pp. 33-39.

[10] T. H. Davenport and L. Prusak, "Working Knowledge: How Organizations Manage What They Know," Harvard Business School Press, Boston, 2000.

[11] P. F. Drucker, "The Age of Social Transformation," The Atlantic Monthly, Vol. 274, No. 5, 1994, pp. 53-58.

[12] J. Yang, L. L. Fang and W. Q. Ling, "Find the Real Meaning of Knowledge Workers," Chinese Talents Magazine, No. 8, 2002, pp. 30-31.

[13] J. Li, Z. R. Chen and G. H. Deng, "Knowledge Workers 
Management Present Situation Analysis and Countermeasures Thinking in Anhui Province," East China Economic Management, No. 6, 2002, pp. 13-14.

[14] J. W. Sun, "Knowledge Workers and Knowledge Work Improvement," Fudan Journal (Social Sciences Edition) No. 3, 1998, pp. 30-32.

[15] J. Davies, R. Studer, Y. Sure and P. W. Warren, "Next Generation Knowledge Management," Technology Journal, Vol. 23, No. 3, 2005, pp. 175-190.

[16] W. Y. Xu and Y. D. Zhu, "Review on Knowledge Worker Research," Modern Business, No. 8, 2009, pp. 99-100.

[17] W. Z. Cai, "The Model Research of Enterprise Knowledge Workers Four Levels Motivation System," Productivity Research, No. 8, 2006, pp. 240-242.

[18] C. L. Zhou, X. X. Wen and X. M. Zhang, "An Empirical Analysis on Motivation Factors with Knowledge Workers," Market Modernization, No. 3, 2006, pp. 241-242.

[19] L. Jiang, "The Characteristic and Management of Knowledge Workers," Economic Theory and Business Management, Vol. 10, No., 2002, pp. 58-62.

[20] J. F. Peng, "The 10 Characteristics of HRM in 21st Century," Chinese Talents Magazine, No. 11, 2000, pp. 1215.

[21] Z. C. Ye. "The management of Knowledge Workers," Journal of Chongqing University (Social Sciences Edition), Vol. 1, No., 2002, pp. 125-126.

[22] M. W. Zhang, "The Soft Management Based on the Characteristics of Knowledge Workers Forward Position No. 9, 2004, pp. 150-153.

[23] X. Y. Cao, "Mode Research on New HRM in Knowledge-based Enterprise," Science of Science and Management of $S$ \& T, No. 4, 2002, pp. 37-39.

[24] T. Q. Zhang and R. G. Ding, "Psychological Contracts for Dynamic Knowledge-based Teamwork," Journal of Dezhou University, No. 3, 2001, pp. 15-19.

[25] H. F. Sun, "Feature of Knowledge Employee and the Corresponding Motivation Principle," Journal of Hefei University of Technology (Social Sciences), Vol. 4, 2004, pp. 70-73.

[26] B. Yu, "Knowledge Workers Performance Appraisal Methods Research," China Economist, No. 5, 2006, p. 145.

[27] T. Li, "Analysis the Challenges and Countermeasures to the HRM in Enterprise of 80s Knowledge Workers," Modern Business, No. 9, 2009, pp. 67-68.

[28] M. Tampoe, "Motivating Knowledge Workers-The Challenge for the 1990s," Long Range Planning, Vol. 26, No. 3, 1993, pp. 49-55.

[29] J. F. Peng and W. J. Zhang, "How to Motivate Knowledge Workers," Human Resource Development of China, No. 9, 1999, pp. 12-14.

[30] Y. L. Deng, W. P. Wang, J. Chen and H. Zhou, "The Incentive Mechanism Based on Risk Appetite Knowledge Workers," Journal of Southeast University (Natural Science Edition), No. 4, 2005, pp. 624-627.

[31] J. A. Chen, G. Y. Jing, "The Empirical Research on Mo- tivation Factors for Knowledge Workers," Science of Science and Management of S \& T, No. 8, 2005, pp. 101-105.

[32] C. Zheng and Y. L. Huang, "The Present Situational Probe and Innovation Strategy of Encouragement Mechanism to Knowledge Employees in State-Owned Enterprises," East China Economic Management, No. 3, 2001, pp. 30-33.

[33] C. Y. Jiang and S. M. Zhao, "Characteristics, Influencing Factors and Countermeasures for Circulation of Knowledge Worker," China Soft Science, No. 2, 2001, pp. 85-88.

[34] J. Z. Zhang, W. Q. Wang and X. Hu, "An Empirical Research on the Motivation Factors and Motivation Tactics of Knowledge Worker in Agricultural High-tech Enterprises," Journal of Beijing Institute of Technology (Social Sciences Edition), No. 6, 2007, pp. 67-72.

[35] Y. L. Guo, "The Analysis of Knowledge Staff's Encouraging Action," Contemporary Finance \& Economics, No. 11, 2002, pp. 63-66.

[36] A. Yan and L. Li, "Incentive Mechanism Design and Utility Analysis of Knowledge Workers," Journal of Hunan College of Financial and Economic, No. 4, 2005, pp. 6771.

[37] J. Xian and H. M. Zhu, "Discussion about the Motivation of the Knowledge-Based Enterprise Employees," Enterprise Economy, No. 8, 2003, pp. 125-126.

[38] J. Li and Y. H. Yu, "Risk Management in Drain of Knowledge Employees," Shandong Social Science, No. 3, 2003, pp. 35-37.

[39] J. M. Sun, "Discussion on Management and Motivation of Knowledge Workers," Journal of Zhongnan University of Finance and Economics, No. 1, 2003, pp. 67-70.

[40] R. Wang and H. Z. Zhang, "Encouragement Measures for Knowledge Workers," Science \& Technology Progress and Policy, No. 4, 2002, pp. 99-100.

[41] Y. J. Chen, The New Exploration on Knowledge Workers Motivation Model," Economics and Management, No. 3, 2004, pp. 67-69.

[42] X. Y. Luo, "The Effective Incentive Aim at the Knowledge Workers" Characteristics," Commercial Times, No. 11, 2004, pp. 20-21.

[43] R. L. Zhang and Y. C. Ding, "The Research Survey of Knowledge Workers Motivation Mechanism," Economical Social Development, No. 3, 2005, pp. 98-100.

[44] L. Y. Ge, D. Jang and L. M. Chi, "The Discussion of Effectively Stimulate Knowledge Workers," East China Economic Management, No. 12, 2006, pp. 117-120.

[45] X. Min and S. Z. Yan, "Based on the Characteristics of Knowledge Workers Motivation Response," Chinese Talents Magazine, No. 5, 2004, pp. 72-73.

[46] C. H. Yang, "A Comparative Analysis on the Motivation Factors of the Knowledge Workers in China and Overseas," Science \& Technology Progress and Policy, No. 6, 2004, pp. 168-170.

[47] Q. Wang and Y. Wang, "The Discussion of Knowledge Workers and Construction of the Motivation System," Modern Economic Research, No. 8, 2001, pp. 44-46. 
[48] Y. J. Chen, "The Status Quo and the Transformation Research of Chinese Family Enterprise Management ModeTake the Zhejiang Family Enterprises for Example," Industrial Technology \& Economy, No. 2, 2004, pp. 37-41.

[49] J. Wang and J. Wang, "Build the Core Competitiveness of the Hotel in the Knowledge Economy Era," China Economic \& Trade Herald, No. 16, 2009, pp. 81-83.

[50] W. Q. Wang, "A Comparative Analysis in China and Overseas and Empirical Research on the Motivation Factors of Knowledge Workers," Journal of University of Electronic Science and Technology of China, No. 2, 2008, pp. 39-43.

[51] H. Y. Liu and C. Q. Wang, "The Research of Knowledge
Workers Motivation Factors and the Engagement," Guide to Business, No. 2, 2010, pp. 202-203.

[52] G. Hofstede, "Cultural Constraints in Management Theories," Academy of Management, Vol. 7, No. 1, 1993, pp. 8-21.

[53] B. G. Zhao and S. T. Wang, "Knowledge Workers Motivation Research within the Knowledge Team," Lanzhou Academic Journal, No. 7, 2006, pp. 154,158-161.

[54] S. Q. Wu and L. Y. He, "The Characteristics of Chinese Knowledge Workers and the Contrast at Home and Abroad," Science and Technology Management Research, No. 2, 2007, pp. 104-106. 